\title{
Costunolide isolated from Vladimiria souliei inhibits the proliferation and induces the apoptosis of HepG2 cells
}

\author{
JINGXIN MAO, MAN YI, YUNYI TAO, YUANSHE HUANG and MIN CHEN \\ College of Pharmaceutical Sciences, Southwest University, Chongqing 400715, P.R. China
}

Received May 10, 2018; Accepted November 5, 2018

DOI: $10.3892 / \mathrm{mmr} .2018 .9736$

\begin{abstract}
Costunolide (cos) is one of the major sesquiterpenes isolated from the ethyl acetate soluble fraction of the roots of Vladimiria souliei. In order to explore the effects and molecular mechanism of cos, the anti-proliferative and apoptotic effects of cos against the human hepatoblastoma HepG2 cell line was examined in vitro in the current study. Cell viability was measured using an MTT assay, and $\mathrm{IC}_{50}$ values (indicating the concentration required to achieve half-maximal inhibition) were calculated to detect the inhibitory effect of cos on HepG2 cell growth. Cell morphology was subsequently observed under an inverted microscope, and cell cycle distribution and apoptosis were detected using flow cytometric analysis. In addition, changes in the protein expression levels of B-cell lymphoma 2 (Bcl-2), Bcl-2-associated X protein (Bax), and caspases-3, -8 and -9 were detected by western blotting. The results of cell analyses indicated that cos treatment inhibited the proliferation and promoted the apoptosis of HepG2 cells in vitro. Cos markedly induced HepG2 cell apoptosis by arresting the cell cycle at the $\mathrm{G}_{2} / \mathrm{M}$ phase in a dose-dependent manner. In terms of the underlying mechanism, cos was revealed to inhibit the anti-apoptotic capacity of the cells, possibly via upregulating the expression levels of Bax protein and caspases-3, -8 and -9 , and downregulating the expression of Bcl-2 protein. Taken together, the results of the present study indicate that cos may be a promising candidate for liver cancer therapy, and have provided an insight into the mechanism of action involved in its anti-cancer properties.
\end{abstract}

\section{Introduction}

Liver cancer is the third leading cause of cancer-associated morbidity and mortality worldwide (1), and primarily results from chronic hepatitis, nonalcoholic fatty liver disease and

Correspondence to: Professor Min Chen, College of Pharmaceutical Sciences, Southwest University, 2 Tiansheng Road, Chongqing 400715, P.R. China

E-mail:mminchen@swu.edu.cn

Key words: costunolide, Vladimiria souliei, apoptosis, HepG2 cells, mechanistic effect other hereditary conditions (2). In recent years, the morbidity and mortality rates associated with liver cancer have shown an increasing tendency (3). Furthermore, due to the difficulties associated with establishing a correct diagnosis during the early stages of the disease, the scarcity of targeted drugs and the accompanying rapid progression of the illness, the survival rate of liver cancer is low (4). At present, surgical methods, including liver transplantation and resection, are the first-choice therapies for the treatment of patients with liver cancer in the early stages of the disease $(5,6)$. However, the majority of patients with liver cancer have already progressed to an advanced stage at the time of diagnosis, having therefore lost the best opportunity for treatment, and must depend on radiotherapy, chemotherapy and other non-surgical treatment methods (7). Therefore, the development of novel and effective preventative and treatment drugs for liver cancer with minimal side effects is an urgent requirement.

Natural products isolated from traditional Chinese medicinal plants are one of the most important sources of anti-cancer drugs that are used for the effective treatment of cancer in China. These may assist patients through enhancing their anticancer ability and working as remedial agents against adverse reactions caused by radiotherapy or chemotherapy (8). The flowering plant species Vladimiria (V.) souliei, classified in the Compositae family, is mainly distributed in the western and eastern Sichuan province and eastern Tibet in China (9). Costunolide (cos) is one of the major sesquiterpenes extracted from $V$. souliei and is considered to be the active constituent of this plant. It has been demonstrated to have various pharmacological properties, including serving as an anti-lung injury, anti-hepatitis B virus and anti-liver injury agent. Cos has also been reported to inhibit ethanol-induced gastric ulcers in mice and to exert anti-cancer effects in vitro (10-14).

Thus far, cos has been extensively studied with respect to its potential anti-cancer activity in vitro. It exhibited strong inhibitory effects on the proliferation of human osteosarcoma U2OS (15), breast cancer MCF-7 (16), bladder cancer T24 (17), leukemia HL-60 (18), and cervical cancer Hela (19) cell lines, indicating that $\cos$ is a potential therapeutic candidate for the treatment of cancer. It was previously reported that cos treatment could inhibit cell proliferation of HepG2 cells $\left(\mathrm{IC}_{50}\right.$ $27.5 \mu \mathrm{M})(20)$; however, to the best our knowledge the protective mechanisms of cos against liver cancer have not been elucidated. 
Therefore, the present study aimed to investigate the effects of cos against liver cancer and to determine whether apoptotic pathways contribute to the anticancer effects of cos in HepG2 cells. The growth inhibitory effects of cos on HepG2 cells were examined using MTT assay, while cell morphology was examined in order to determine the extent of cellular apoptosis. Cell cycle distribution and apoptosis analyses were also conducted using flow cytometry. The protein expression levels of B-cell lymphoma 2 (Bcl-2), Bcl-2-associated X protein (Bax), and caspases-3, -8 and -9 were further detected by western blotting. It was demonstrated that cos effectively inhibited the proliferation and induced the apoptosis of HepG2 cells. Taken together, the results of the present study suggested that cos may be a promising therapeutic agent for the treatment of liver cancer, and the potential mechanism underlying its effects was, in part, elucidated.

\section{Materials and methods}

Plant material. The roots of $V$. souliei were identified by Professor Min Chen, the corresponding author of the present study, of the College of Pharmaceutical Sciences, Southwest University (Chongqing, China). The plants were collected at Luding County (Sichuan, China) in October 2015, and a voucher specimen (no. 2015-14) was deposited at the College of Pharmaceutical Sciences, Southwest University.

Extraction and isolation of cos. Powder derived from the air-dried roots $(11.0 \mathrm{~kg})$ of $V$. souliei was extracted three times with $95 \%$ ethanol overnight at room temperature. The ethanol extract was evaporated in vacuo to yield a semisolid $(1.12 \mathrm{~kg})$, which was then suspended in water and partitioned successively with petroleum ether, ethyl acetate and n-butanol. The ethyl acetate solution was concentrated to yield $296 \mathrm{~g}$ of residue, which was subjected to silica gel column chromatography elution with petroleum ether/ethyl acetate, using mixtures of increasing polarity (99:1 to 10:1) to obtain a total of 16 fractions. Cos (4.23 g) was purified from fraction 7 (purity, $>98 \%$ ) by crystallization and recrystallization, and its structure was confirmed by spectroscopic methods, including ${ }^{1} \mathrm{H}$-nuclear magnetic resonance and mass spectrometric analyses, by comparing with data in the literature (21).

Reagents and materials. Human liver cancer HepG2 cells were purchased from Shanghai Institute of Cell Biology, Chinese Academy of Sciences (Shanghai, China). Dimethyl sulfoxide (DMSO), the Annexin V/fluorescein isothiocyanate (FITC) apoptosis detection kit were purchased from Nanjing KeyGen Biotech Co., Ltd. (Nanjing, China). Dulbecco's modified Eagle's medium (DMEM), fetal bovine serum (FBS), streptomycin and penicillin were purchased from Thermo Fisher Scientific, Inc. (Waltham, MA, USA). The MTT assay kit, cell cycle analysis kit, rabbit monoclonal primary antibodies against $\beta$-actin (cat. no. AF0003), Bax (cat. no. AF1270), Bcl-2 (cat. no. AF1915), caspase-3 (cat. no. AF1213), caspase-8 (cat. no. AF1243) and caspase-9 (cat. no. AF1264), and horseradish peroxidase-conjugated secondary antibodies (cat. no. A0208) were purchased from Beyotime Institute of Biotechnology
(Shanghai, China). Cos (purified via recrystallization to a purity $>98 \%$, as described above) was dissolved in DMSO and stored at $4^{\circ} \mathrm{C}$.

Cell culture and treatment. HepG2 cells were cultured in DMEM supplemented with $10 \% \mathrm{FBS}, 100 \mu \mathrm{g} / \mathrm{ml}$ streptomycin and $100 \mu \mathrm{g} / \mathrm{ml}$ penicillin at $37^{\circ} \mathrm{C}$ in a humidified atmosphere containing $5 \% \mathrm{CO}_{2}$. Cells in the control group were treated with DMSO, whereas HepG2 cells in the experimental groups were exposed to $2.5,5,10,20$ and $40 \mu \mathrm{mol} / 1 \cos$ for 3,6 , $12,24,36$ and $48 \mathrm{~h}$. In the cos treatment groups, the final concentration of DMSO added to the cells was $<0.1 \%$.

Microscopic observation. Morphological changes associated with apoptosis were assessed using light microscopy. Following the corresponding treatments, the morphology of HepG2 cells was observed under an inverted light microscope (Olympus CKX53; Olympus Corporation, Tokyo, Japan), and images were captured at a magnification of x100.

Cell viability assay. MTT assay was used to measure the viability of the HepG2 cells. Briefly, cells were plated in 96-well culture plates $\left(1 \times 10^{4}\right.$ cells/well) and incubated at $37^{\circ} \mathrm{C}$ with cos at various concentrations $(2.5,5,10,20$, and $40 \mu \mathrm{mol} / \mathrm{l})$ for $48 \mathrm{~h}$. In addition, cells were treated with $10 \mu \mathrm{mol} / \mathrm{l}$ cos for 3 , $6,12,24,36$ and $48 \mathrm{~h}$. Subsequently, MTT solution $(5 \mathrm{mg} / \mathrm{ml})$ was added to each well. After $3 \mathrm{~h}$ of incubation, the formazan precipitate was dissolved in $100 \mathrm{ml} \mathrm{DMSO}$, and the absorbance was measured at a wavelength of $450 \mathrm{~nm}$ using a microplate reader (Bio-Rad 550; Bio-Rad Laboratories, Inc., Hercules, CA, USA). The half-maximal inhibitory concentration $\left(\mathrm{IC}_{50}\right)$ values were calculated by nonlinear regression analysis using Origin version 8.0 (OriginLab Software, Inc., Northampton, MA, USA) and GraphPad Prism version 5.0 (GraphPad Software, Inc., La Jolla, CA, USA) software packages. Each sample was analyzed in triplicate.

Cell cycle analysis. Cell cycle distribution was analyzed using flow cytometric analysis. Briefly, cells were plated in $10-\mathrm{cm}$ plates, and treated with DMSO or with the various concentrations $(2.5,5,10,20$, and $40 \mu \mathrm{mol} / \mathrm{l})$ of $\cos$ for $48 \mathrm{~h}$. Subsequently, the treated cells were collected, washed twice with cold phosphate-buffered saline (PBS), fixed with $70 \%$ ethanol and stained with propidium iodide (PI). The cells were then analyzed using a flow cytometer (Accuri C6; Bio-Rad Laboratories, Inc.), and the data obtained were analyzed with FlowJo software (version X; FlowJo LLC, Ashland, OR, USA).

Apoptosis assay. Cells were treated with DMSO or various concentrations $(2.5,5,10,20$, and $40 \mu \mathrm{mol} / \mathrm{l})$ of cos. After $48 \mathrm{~h}$ of incubation, the cells were harvested and washed twice in cold PBS for cell apoptotic analysis. The cells were subsequently treated with $5 \mu \mathrm{l}$ Annexin V/FITC and $5 \mu \mathrm{l}$ PI solution, and then incubated at room temperature for $15 \mathrm{~min}$ in the dark. Finally, the cells were analyzed for apoptosis using an Accuri C6 flow cytometer. According to the protocol provided with the apoptosis kit, the number of cells in each cell cycle phase was calculated using Cell ModFit software (BD Biosciences, Franklin Lakes, NJ, USA). The experiments were performed in triplicate. The apoptotic rate was the sum of 
A

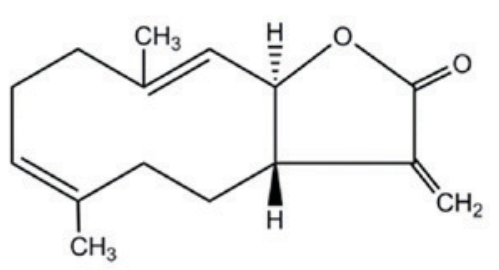

C

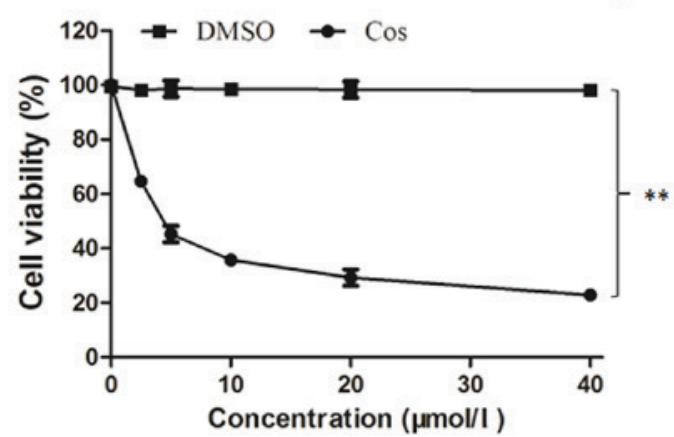

B
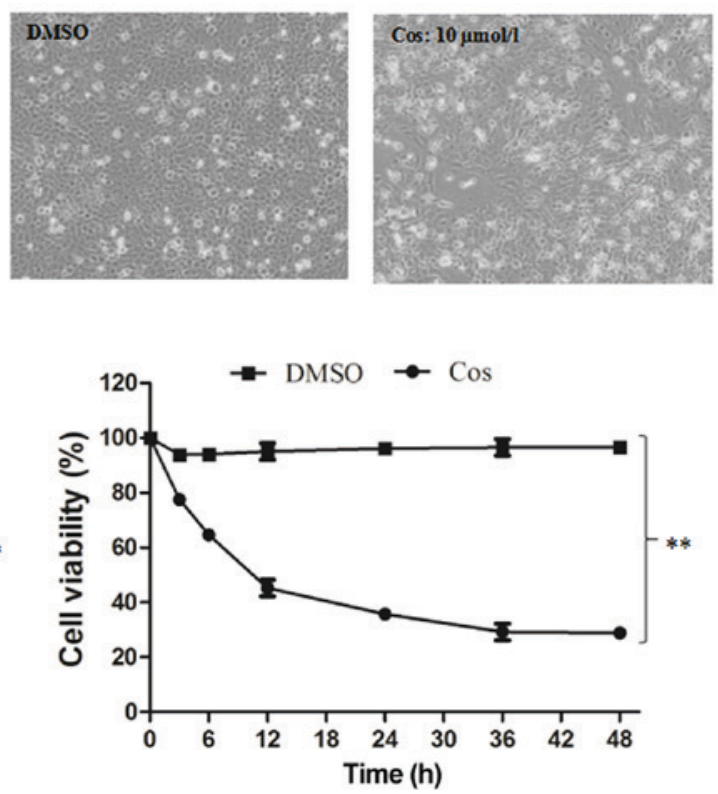

Figure 1. Effect of cos on the morphology and proliferation of HepG2 cells. (A) Chemical structure of cos. (B) Morphological changes of HepG2 cells cultured with DMSO or $10 \mu \mathrm{mol} / 1 \mathrm{cos}$ for $48 \mathrm{~h}$ were observed using an inverted microscope (magnification, x100). An MTT assay was conducted to measure the viability of HepG2 cells treated with (C) cos (2.5-40 $\mu$ mol/1) for $48 \mathrm{~h}$, or (D) $10 \mu \mathrm{mol} / 1$ cos for 3, 6, 12, 24, 36 and 48 h, respectively. DMSO treatment was used as a control. Data are expressed as the mean \pm standard deviation from triplicate determinations. ${ }^{* *} \mathrm{P}<0.01$. Cos, costunolide; DMSO, dimethyl sulfoxide.

the proportion of cells in the early (Annexin $\mathrm{V} / \mathrm{FITC}^{+} \mathrm{PI}^{-}$) and late (Annexin $\mathrm{V} / \mathrm{FITC}^{+} \mathrm{PI}^{+}$) stages of apoptosis.

Western blot assay. Approximately $5 \times 10^{5}$ HepG2 cells plated in 6-well culture plates were used for western blotting. Total protein fractions were isolated, the medium was removed, and cells were washed twice with ice-cold PBS prior to lysis using cell lysis buffer (containing $20 \mathrm{mM}$ Tris, $150 \mathrm{mM}$ $\mathrm{NaCl}$ and $1 \%$ Triton $\mathrm{X}-100)$. The lysates were collected by scraping from the plates and subsequently centrifuged at $12,000 \times \mathrm{g}$ at $4^{\circ} \mathrm{C}$ for $5 \mathrm{~min}$. Protein concentrations were determined using the BCA protein assay method (Beyotime Institute of Biotechnology). Samples (50 $\mu \mathrm{g})$ were separated by SDS-PAGE (10\% gels) and subsequently transferred onto nitrocellulose membranes for $1.5 \mathrm{~h}$. Following blocking with $10 \%$ dried fat-free milk in Tris-buffered saline buffer with $0.05 \%$ Tween-20 for $1 \mathrm{~h}$ at $37^{\circ} \mathrm{C}$, the membranes were incubated with the primary antibodies overnight at $4^{\circ} \mathrm{C}$. The primary antibodies used were as follows: Anti-Bax (1:1,000 dilution), anti-Bcl-2 (1:1,000), anti-caspases-3, -8 and -9 (1:1,000), and anti- $\beta$-actin $(1: 1,500)$. Subsequently, the membranes were incubated with secondary goat anti-rabbit antibodies $(1: 1,000)$ at $37^{\circ} \mathrm{C}$ for $1 \mathrm{~h}$. Proteins were detected using an EasyBlot ECL kit (cat. no. C506668-0100; Sangon Biotech Co., Ltd., Shanghai, China). Using ImageJ software version 1.50 (National Institutes of Health, Bethesda, MD, USA) for grayscale analysis, the relative expression levels of the target proteins were expressed as the ratio of the gray value of Bax, caspase-3, caspase- 8 , caspase -9 and $\mathrm{Bcl}-2$ protein to the gray value of $\beta$-actin.

Statistical analysis. Data are expressed as the mean \pm standard deviation. SPSS software version 18.0 (SPSS, Inc., Chicago, IL, USA) was used to perform statistical analyses. One-way analysis of variance followed by least significant difference post hoc test was used to compare data containing multiple groups. Student's t-test was performed to determine statistically significant differences between two groups. $\mathrm{P}<0.05$ was considered to indicate statistically significant values.

\section{Results}

Effect of cos on the proliferation and morphology of HepG2 cells. The chemical structure of cos, which is a sesquiterpene lactone with an $\alpha$-methylene- $\gamma$-lactone ring, is shown in Fig. $1 \mathrm{~A}$. HepG2 cells in the DMSO group appeared to have a regular phenotype and to adhere to the wall of the plate, as observed in images captured under an inverted microscope (Fig. 1B). By contrast, the majority of the cells pretreated with $10 \mu \mathrm{mol} / 1 \mathrm{cos}$ for $48 \mathrm{~h}$ appeared to have a smaller volume, irregular shape and smaller size, while they were separated from adjacent cells and lost their adhesive property, revealing a clear reduction in their proliferative capacity. At the end of the treatment period, the adhesion of these cells gradually declined, and they eventually separated and floated freely (Fig. 1B). Furthermore, the results revealed that cos effectively inhibited the proliferation of HepG2 cells in a dose-dependent manner, as compared with the DMSO-treated cell group (Fig. 1C). After $48 \mathrm{~h}$ of treatment with cos, the $\mathrm{IC}_{50}$ was determined to be $18.09 \pm 1.74 \mu \mathrm{M}$. The inhibitory effect of cos was also induced in a time-dependent manner, with the proliferation of HepG2 cells progressively decreasing over the time course of the experiment $(3,6,12,24$, 36 and 48 h), as shown in Fig. 1D. Taken together, these results suggested that cos effectively inhibited HepG2 cell proliferation in a dose- and time-dependent manner.

Effect of cos on cell cycle distribution of HepG2 cells. HepG2 cells in the control group were treated with DMSO, whereas cells in the experimental groups were exposed to 2.5, 5, 10, 20 and $40 \mu \mathrm{mol} / \mathrm{l}$ cos for $48 \mathrm{~h}$. PI staining and flow cytometric analysis 

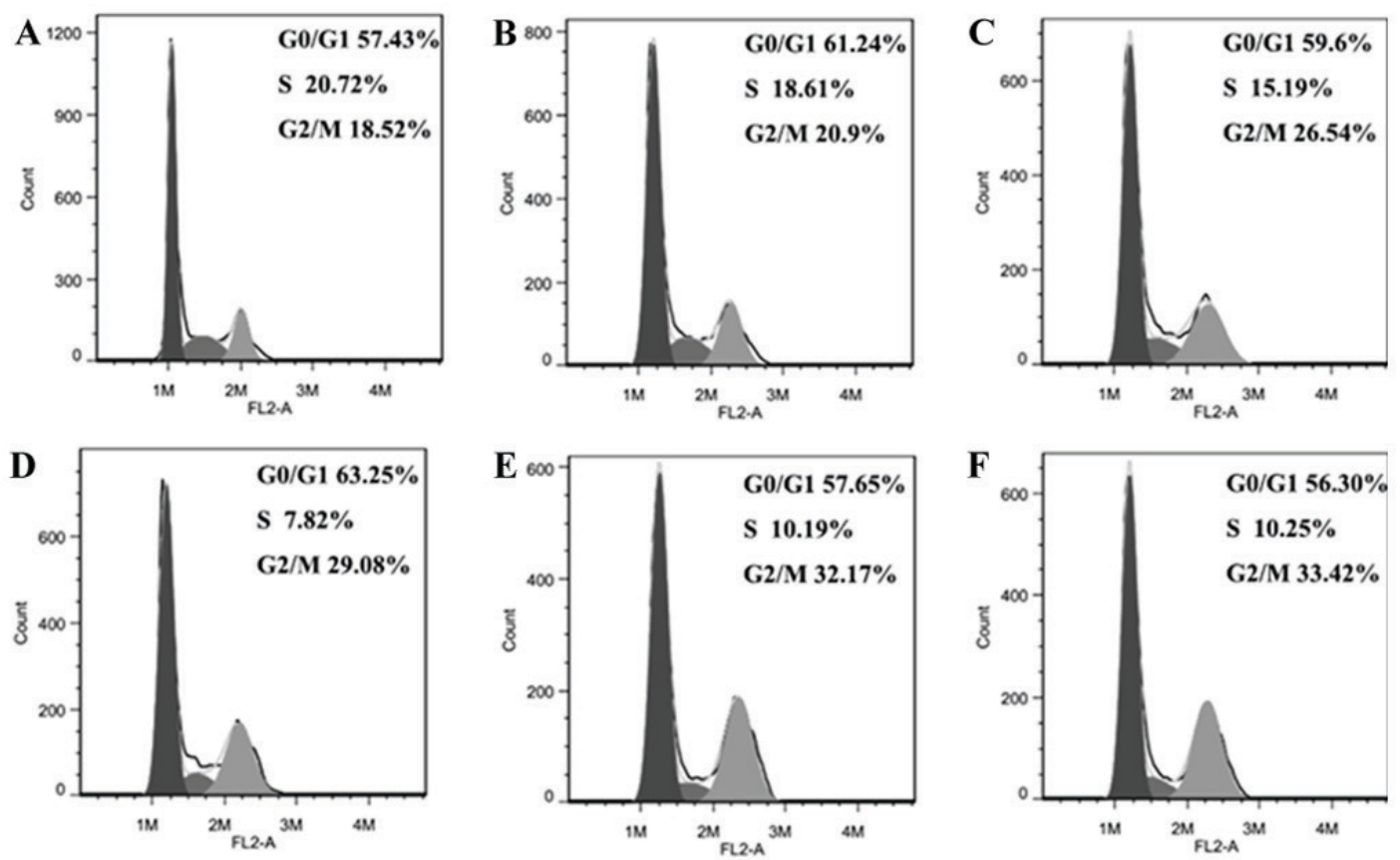

G

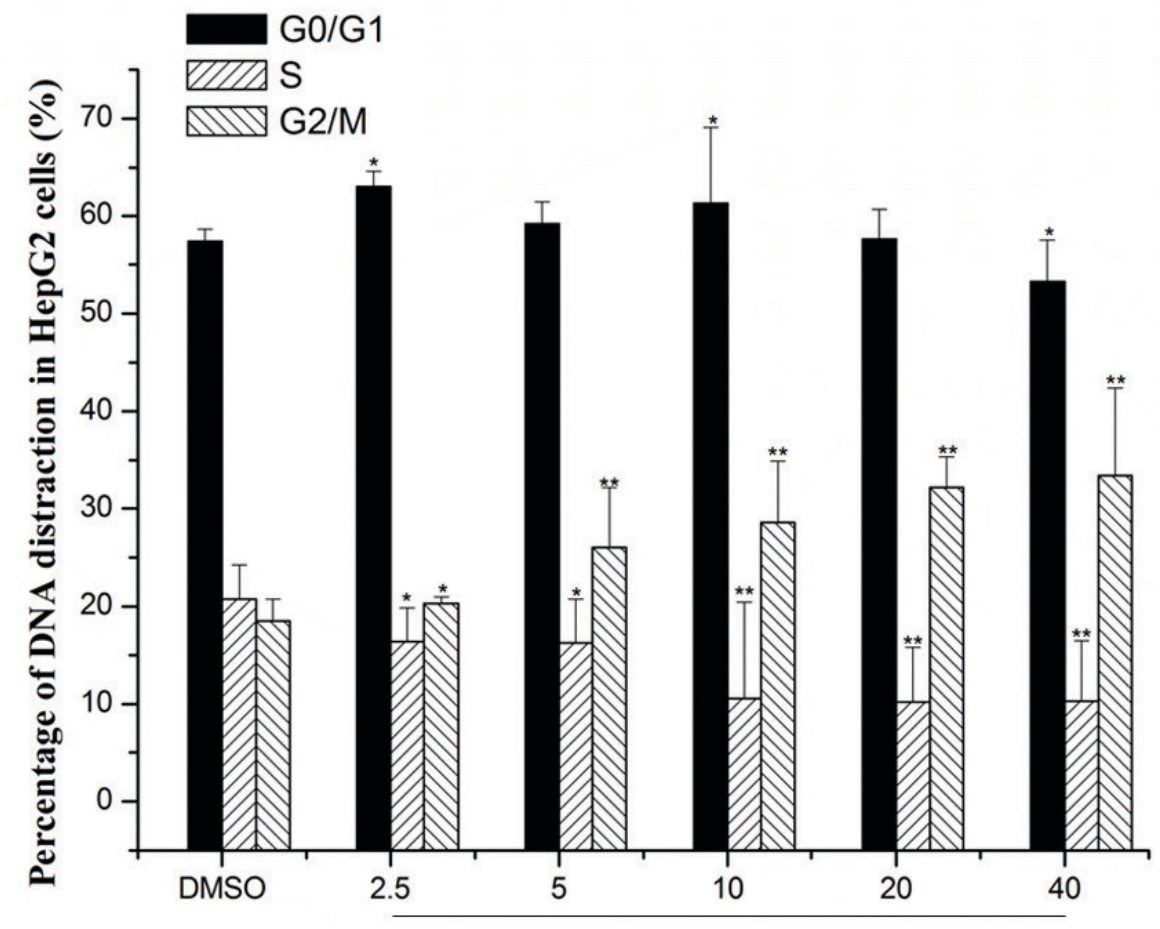

$\operatorname{Cos}(\mu \mathrm{mol} / \mathbf{l} ; 48 \mathrm{~h})$

Figure 2. Effect of cos on cell cycle distribution of HepG2 cells. Following stimulation with cos or DMSO for 48 h, HepG2 cells were harvested, fixed with ethanol and stained with propidium iodide. The number of cells at each cell cycle phase was subsequently determined using flow cytometry in cells treated with (A) DMSO, or with (B) $2.5 \mu \mathrm{mol} / 1$, (C) $5 \mu \mathrm{mol} / 1$, (D) $10 \mu \mathrm{mol} / 1$, (E) $20 \mu \mathrm{mol} / 1$ and (F) $40 \mu \mathrm{mol} / 1 \mathrm{cos}$, respectively. (G) Percentages of HepG2 cells at each phase of the cell cycle, analyzed using Origin version 8.0 software. Data are expressed as the mean \pm standard deviation from triplicate determinations. ${ }^{*} \mathrm{P}<0.05$ and ${ }^{* *} \mathrm{P}<0.01$, vs. control (DMSO) group. Cos, costunolide; DMSO, dimethyl sulfoxide.

were used to detect the effect of cos on the cell cycle distribution of HepG2 cells, and the results are shown in Fig. 2. Compared with the DMSO-treated group, the percentage of cells in $\mathrm{G}_{1} / \mathrm{G}_{0}$ phase following treatment with the various concentrations of cos did not change significantly, whereas the percentage of cells in the $\mathrm{G}_{2} / \mathrm{M}$ phase was significantly increased and that in $\mathrm{S}$ phase was significantly decreased. Following treatment with $0,2.5,5$, 10,20 and $40 \mu \mathrm{mol} / \mathrm{l} \cos$ for $48 \mathrm{~h}$, the percentage of HepG2 cells in the $\mathrm{G}_{2} / \mathrm{M}$ phase was $18.52 \pm 2.58,20.90 \pm 4.21,26.54 \pm 3.67$, $29.08 \pm 6.32,32.17 \pm 3.14$ and $33.42 \pm 8.97 \%$, respectively. These results suggested that cos treatment led to cell cycle arrest at $\mathrm{G}_{2} / \mathrm{M}$ phase in a dose-dependent manner.

Effect of cos on the apoptosis of HepG2 cells. Translocation of phosphatidylserine (PS) to the outer leaflet of the cellular membrane is the key step in the early stages of apoptosis. 

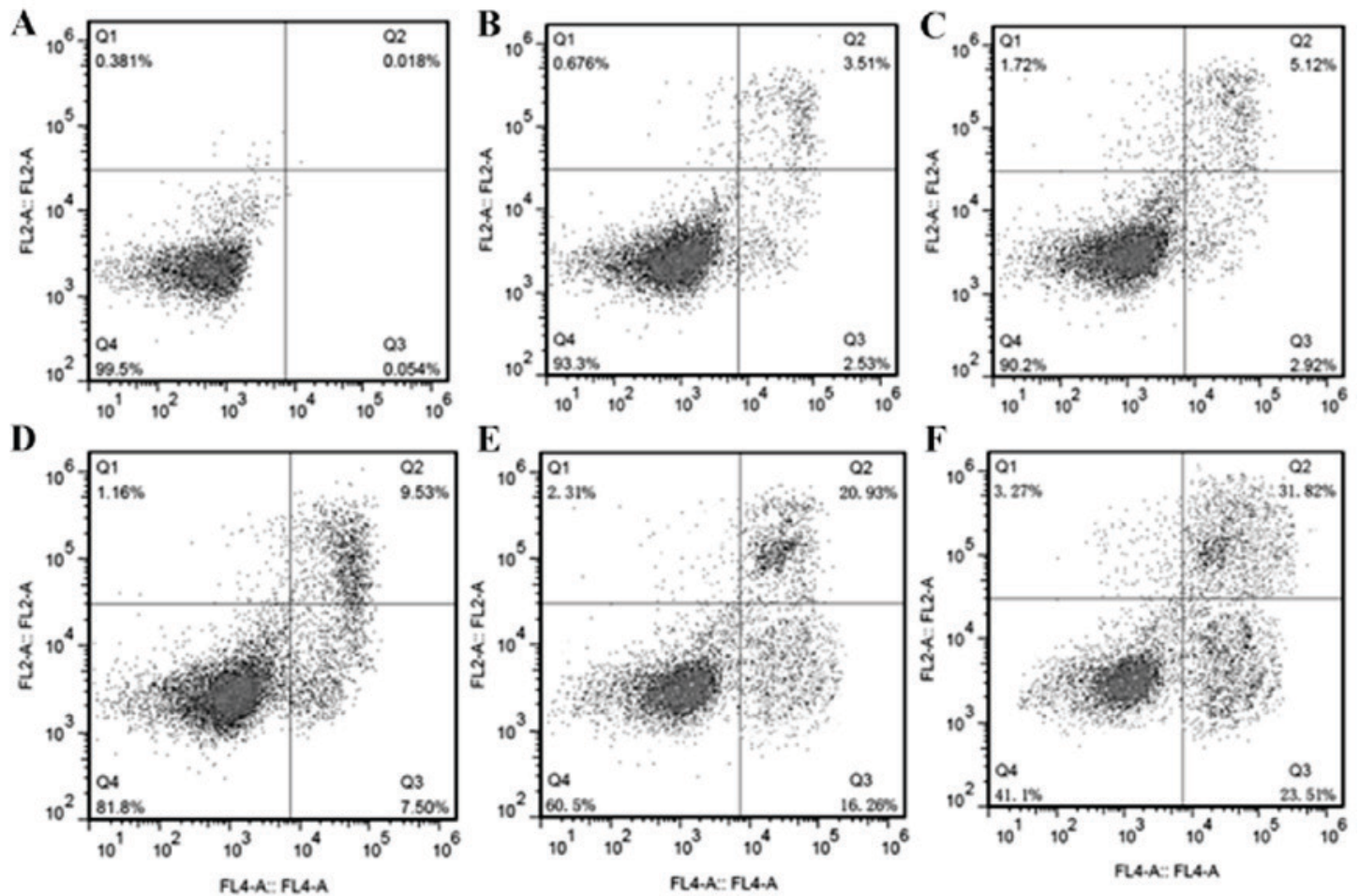

\section{G}

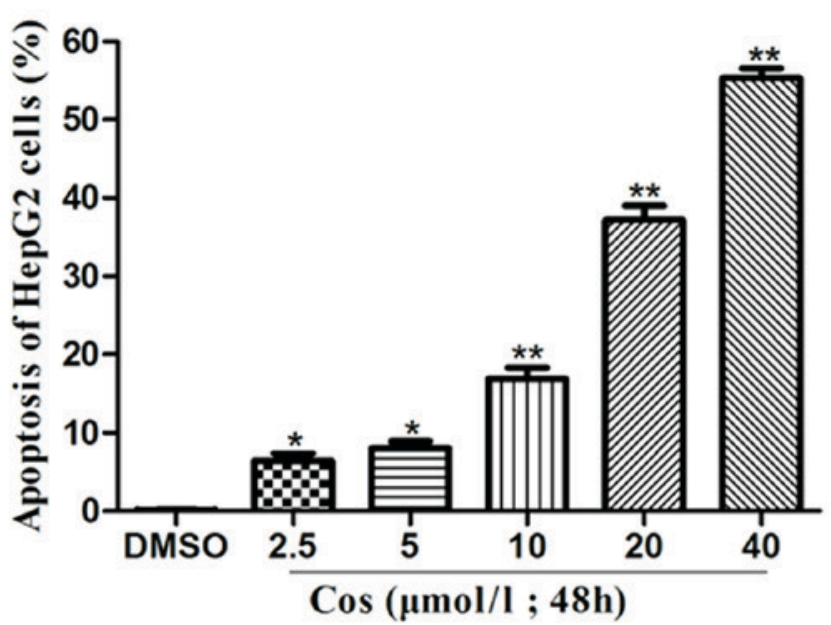

Figure 3. Effect of cos on apoptosis of HepG2 cells. HepG2 cells were treated with cos or DMSO for $48 \mathrm{~h}$, and then stained with fluorescein isothiocyanate-conjugated Annexin $\mathrm{V}$ in a buffer containing propidium iodide, followed by flow cytometric analysis. The flow cytometry results are shown for cells treated with (A) DMSO, or with (B) $2.5 \mu \mathrm{mol} / 1$, (C) $5 \mu \mathrm{mol} / 1$, (D) $10 \mu \mathrm{mol} / 1$, (E) $20 \mu \mathrm{mol} / 1$ and (F) $40 \mu \mathrm{mol} / 1 \mathrm{cos}$. (G) Percentages of apoptotic HepG2 cells, analyzed using GraphPad Prism version 5.0 software. Data are expressed as the mean \pm standard deviation from triplicate determinations. ${ }^{*} \mathrm{P}<0.05$ and ${ }^{* *} \mathrm{P}<0.01$, vs. control (DMSO) group. Cos, costunolide; DMSO, dimethyl sulfoxide.

Annexin V selectively binds to PS, and this process enables the identification of cells undergoing apoptosis. Different populations of cells may be observed when cells are double-stained with Annexin V and PI (22). HepG2 cells in the control group were treated with DMSO, whereas the treatment groups were exposed to $2.5,5,10,20$ and $40 \mu \mathrm{mol} / 1$ cos for $48 \mathrm{~h}$. As revealed in Fig. 3, the apoptotic rate of the HepG2 cells increased significantly with an increasing concentration of cos. The apoptotic rates of HepG2 cells upon treatment with $2.5,5,10,20$ and $40 \mu \mathrm{mol} / 1$ cos were $6.04 \pm 1.24,8.04 \pm 1.57$, $17.03 \pm 2.31,37.19 \pm 3.19$ and $55.33 \pm 2.12 \%$, respectively.

Effect of the cos on the expression levels of caspases-3, -8 and -9, Bax and Bcl-2 in HepG2 cells. Bax and Bcl-2 proteins exert pivotal roles in caspase activation and the regulation of apoptosis (23). In addition, caspase family proteins, the central components of the apoptotic response, are a conserved family of enzymes that induce irreversible cell death (24). Caspases-3, -8 and -9 stand at the nexus of critical regulatory networks controlling cell apoptosis, and are components of the pathway that ultimately mediates the activation and execution of apoptosis. Therefore, the levels of caspases- $3,-8$ and -9 , as well as Bax and $\mathrm{Bcl}-2$ proteins, were investigated in the present study. Cos treatment was observed to induce the apoptosis of HepG2 cells by upregulating the protein expression levels of Bax, and caspases-3, -8 and -9 , and by downregulating the expression of $\mathrm{Bcl}-2$ protein in a dose-dependent manner after $48 \mathrm{~h}$ of treatment (Fig. 4). 
Taken together, these results suggested that cos exerted an inhibitory effect on the growth of HepG2 cells.

\section{Discussion}

Cos, a sesquiterpene lactone that contains an $\alpha$-methylene- $\gamma$-lactone ring structure, belongs to a class of compounds that react with enzymes containing thiol groups and their functional proteases, and interfere with the key biological processes of cells, exhibiting a variety of pharmacological activities (25). It has been reported that cos exerts a strong inhibitory effect on the proliferation and apoptosis of a variety of tumor cells at concentrations ranging between 2.5 and $40 \mu \mathrm{mol} / 1$ (15-19). Therefore, in the present study, the concentrations of $2.5,5,10,20$ and $40 \mu \mathrm{mol} / 1$ cos were selected for investigation. The results demonstrated that cos was able to inhibit the proliferation of HepG2 cells in a concentration-dependent manner, according to cytotoxicity analysis.

Carcinogenesis is a multistep process that may be activated by alterations in the activity of oncogenes and transcription, and such changes affect cell proliferation, cell cycle regulation and cell apoptosis (26). Since abnormal proliferation is observed in cancer cells, inhibition of cell cycle progression is an important means of intervention in the treatment of cancer. Multiple checkpoints regulate cell proliferation during cell cycle progression (27). In the present study, it was identified that cos arrested the cell cycle at the $G_{2} / M$ phase, induced apoptosis in vitro.

It has been reported that the volatile oil and cos obtained from the roots of Saussurea lappa markedly inhibited the proliferation of SMMC-7721 and Hep3B cells in vitro (28). The anti-cancer mechanism of volatile oil on HepG2 cells may be attributed to increases in the proportion of cells in the $G_{2} / M$ and $S$ phases, accompanied by a decrease in the $G_{0} / G_{1}$ phase. In a previous study examining the effect of cos on SGC-7901, apoptosis of the SGC-7901 cells was induced by cos in a time-dependent manner, and the cell cycle was blocked in the $\mathrm{G}_{2} / \mathrm{M}$ phase (29). These previous findings are in agreement with the results of the present study.

Apoptosis is the physiological process of programmed cell death that results in tissue damage. For the majority of commonly used anticancer drugs, activation of apoptotic pathways in order to kill cancer cells remains the predominant anticancer mechanism (30). A previous study indicated that there are two apoptotic pathways that may be activated: The mitochondria-dependent 'intrinsic' cytochrome $c /$ caspase-9 pathway, and the death receptor-mediated 'extrinsic' caspase- 8 pathway (31). In particular, the mitochondrial pathway is considered to be involved in the apoptosis of cancer cells induced by phytochemicals (32). It is known that suppression of anti-apoptotic members or activation of pro-apoptotic members of the Bcl-2 family usually leads to an altered mitochondrial membrane permeability, which subsequently induces apoptosis (33). The Bcl-2 family of proteins contains the anti-apoptotic protein $\mathrm{Bcl}-2$ and the pro-apoptotic protein Bax, which inhibit or promote apoptosis, respectively. These proteins have been described as critical regulators of the mitochondrial apoptosis pathway, regulating mitochondrial membrane permeability to control
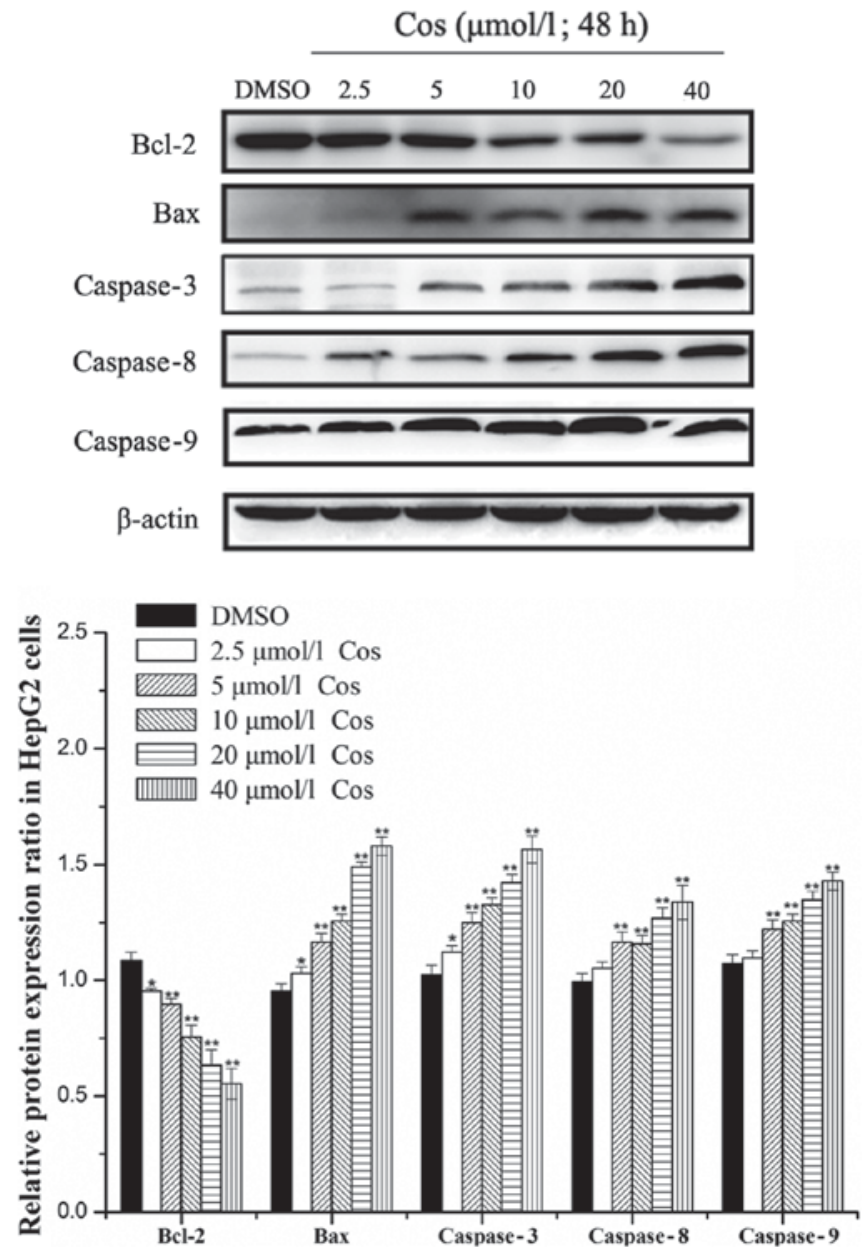

Figure 4. Expression of apoptotic and anti-apoptotic markers in HepG2 cells, including Bcl-2, Bax, and caspases-3, -8 and -9 . Western blotting analysis was used to detect the protein expression levels of these markers, with $\beta$-actin serving as an internal control. The results were analyzed using Origin version 8.0 software. Data are expressed as the mean \pm standard deviation from triplicate determinations. ${ }^{*} \mathrm{P}<0.05$ and ${ }^{* *} \mathrm{P}<0.01$, vs. control (DMSO) group. Cos, costunolide; DMSO, dimethyl sulfoxide.

mitochondrial apoptosis (34). Caspase family proteins also serve a key role in inducing apoptosis, and are involved in the ultimate pathway for the execution of apoptosis. Caspase- 3 is the key protease of apoptosis; when it is activated, the cascade pathway of downstream apoptosis is inevitably triggered (35). Caspase-9, an essential initiator caspase required for apoptosis signaling through the mitochondrial pathway, is activated on the apoptosome complex (36). Caspase- 8 is considered to be predominantly a pro-apoptotic protease that is mainly involved in signal transduction via death receptors of the tumor necrosis factor receptor family, such as Fas (37). Therefore, in the present study, the effects of cos on the expression levels of critical regulators of the mitochondrial apoptotic pathway, including Bax, Bcl-2, and caspases-3, -8 and -9, were examined in HepG2 cells. Western blotting revealed that cos induced apoptosis of HepG2 cells via the upregulation of Bax and caspases-3, -8 and -9 , and the downregulation of Bcl-2 protein expression. A previous study indicated that cos may induce apoptosis in the breast cancer cell line MDA-MB-231 via the activation of Fas in the exogenous pathway, upregulation of caspases- 8 and -3 , and downregulation of poly 
(ADP-ribose) polymerase (PARP) expression (38). In addition, the apoptosis of SGC-790 cells has been reported to be induced by cos via downregulation of the expression levels of Bcl-2 and upregulation of caspase-3 (29). It was also reported that, in the human platinum-resistant ovarian cancer cell line SKOV3PT, cos exerted a clear inhibitory effect by downregulating the activation of $\mathrm{Bcl}-2$ protein and upregulating caspases involved in the apoptosis signaling pathway (39). Furthermore, apoptosis of esophageal cancer cells induced by cos was revealed to be mediated by upregulation of Bax protein expression, downregulation of Bcl-2 protein expression, and activation of caspase- 3 and PARP (40). The results of these previous studies on the anti-cancer effects of cos are consistent with those obtained in the present study. Taken together, these results confirm that cos treatment induced the activation of apoptosis.

In conclusion, the present study demonstrated that cos, a natural sesquiterpene lactone isolated from $V$. souliei, markedly inhibited the proliferation of HepG2 cells in vitro. The survival rate of tumor cells was gradually decreased as the concentration of cos was increased. Furthermore, the apoptosis rates of HepG2 cells increased with an increasing concentration of cos in the range of 2.5-40 $\mu \mathrm{mol} / \mathrm{l}$. Cos was also demonstrated to induce cell cycle arrest in the $\mathrm{G}_{2} / \mathrm{M}$ phase, thereby affecting the proliferation of HepG2 cells. In terms of the underlying mechanism, cos was able to induce apoptosis in the HepG2 cells by upregulating the protein expression levels of Bax and caspases-3, -8 and -9 , and downregulating the expression of Bcl-2 protein, thereby inhibiting the growth of the HepG2 cells. Taken together, these results suggest that cos may be a promising candidate or leading compound for drug development, targeting liver cancer. This study has verified previous results on the inhibitory effects of cos on $\mathrm{HepG} 2$ cells and has also provided preliminary data in support of further animal experiments and clinical trials.

\section{Acknowledgements}

The authors would like to thank Dr Selvaraj Subramaniyam (College of Pharmaceutical Sciences, Southwest University) for his assistance with useful discussions and a critical reading of the manuscript.

\section{Funding}

The present study was supported by the Chongqing Social Undertaking and Livelihood Security Project (grant no. cstc2017shmsA130079) and the National Natural Science Foundation of China (grant no. 81774005).

\section{Availability of data and materials}

The datasets used and/or analyzed during the current study are available from the corresponding author on reasonable request.

\section{Authors' contributions}

MC conceived and designed the study. JM performed most of the experiments and wrote the paper. MY and YT performed part of the experiments. YH analyzed the data.

\section{Ethics approval and consent to participate}

Not applicable.

\section{Patient consent for publication}

Not applicable.

\section{Competing interests}

The authors declare they have no competing interests.

\section{References}

1. Firtina Karagonlar Z, Koc D, Iscan E, Erdal E and Atabey N: Elevated hepatocyte growth factor expression as an autocrine c-Met activation mechanism in acquired resistance to sorafenib in hepatocellular carcinoma cells. Cancer Sci 107: 407-416, 2016.

2. Bosch FX, Ribes J, Díaz M and Cléries R: Primary liver cancer: Worldwide incidence and trends. Gastroenterology 127 (5 Suppl 1): S5-S16, 2004

3. Fu J and Wang HY: Precision diagnosis and treatment of liver cancer in China. Cancer Lett 412: 283-288, 2018.

4. Laursen L: A preventable cancer. Nature 516: S2-S3, 2014.

5. Jarnagin WR: Management of small hepatocellular carcinoma: A review of transplantation, resection, and ablation. Ann Surg Oncol 17: 1226-1233, 2010.

6. Bitzer M, Horger M, Giannini EG, Ganten TM, Wörns MA, Siveke JT, Dollinger MM, Gerken G, Scheulen ME, Wege H, et al: Resminostat plus sorafenib as second-line therapy of advanced hepatocellular carcinoma-The SHELTER study. J Hepatol 65: 280-286, 2016.

7. Kojiro M: Histopathology of liver cancers. Best Pract Res Clin Gastroenterol 19: 39-62, 2005.

8. Lin WF, Lu JY, Cheng BB and Ling CQ: Progress in research on the effects of traditional Chinese medicine on the tumor microenvironment. J Integr Med 15: 282-287, 2017.

9. Chinese Pharmacopoeia Commission: Pharmacopoeia of the People's Republic of China. Vol 1. China Medical Science Press, Shanghai, pp35-36, 2015.

10. Butturini E, Di Paola R, Suzuki H, Paterniti I, Ahmad A, Mariotto S and Cuzzocrea S: Costunolide and dehydrocostuslactone, two natural sesquiterpene lactones, ameliorate the inflammatory process associated to experimental pleurisy in mice. Eur J Pharmacol 730: 107-115, 2014.

11. Chen HC, Chou CK, Lee SD, Wang JC and Yeh SF: Active compounds from Saussurea lappa Clarks that suppress hepatitis B virus surface antigen gene expression in human hepatoma cells. Antiviral Res 27: 99-109, 1995.

12. Wang Y,Zhang X, Zhao L, Shi M, Wei Z, Yang Z, Guo C and Fu Y: Costunolide protects lipopolysaccharide/d-galactosamine-induced acute liver injury in mice by inhibiting NF- $\mathrm{B}$ signaling pathway. J Surg Res 220: 40-45, 2017.

13. Zheng H, Chen Y, Zhang J, Wang L, Jin Z, Huang H, Man S and Gao W: Evaluation of protective effects of costunolide and dehydrocostuslactone on ethanol-induced gastric ulcer in mice based on multi-pathway regulation. Chem Biol Interact 250: 68-77, 2016

14. Srivastava SK, Abraham A, Bhat B, Jaggi M, Singh AT, Sanna VK, Singh G, Agarwal SK, Mukherjee R and Burman AC: Synthesis of 13-amino Costunolide derivatives as anticancer agents. Bioorg Med Chem Lett 16: 4195-4199, 2006.

15. Zhang C, Lu T, Wang GD, Ma C and Zhou YF: Costunolide, an active sesquiterpene lactone, induced apoptosis via ROS-mediated ER stress and JNK pathway in human U2OS cells. Biomed Pharmacother 80: 253-259, 2016.

16. Wang GM, Shi DD, Peng ZX, Lu YF, Gu X, Wang Y and Yan C: Study on mechanism of costunolide-induced apoptosis in breast cancer MCF-7 cells. Chin J Anal Chem 43: 682-688, 2015.

17. Rasul A, Bao R, Malhi M, Zhao B, Tsuji I, Li J and Li X: Induction of apoptosis by costunolide in bladder cancer cells is mediated through ROS generation and mitochondrial dysfunction. Molecules 18: 1418-1433, 2013. 
18. Oh GS, Pae HO, Chung HT, Kwon JW, Lee JH, Kwon TO, Kwon SY, Chon BH and Yun YG: Dehydrocostus lactone enhances tumor necrosis factor-alpha-induced apoptosis of human leukemia HL-60 cells. Immunopharmacol Immunotoxicol 26: 163-175, 2004.

19. Semsarha F, Taheri MA and Najafi MH: Interfering with consciousness at cellular (HeLa cell) and molecular (microtubule protein) levels. Presented at The Science of Consciousness TSC 2016. Abstract 299, 2016.

20. Wang Z, Zhao Z and Gong XG: Costunolide induces lung adenocarcinoma cell line A549 cells apoptosis through ROS (reactive oxygen species)-mediated endoplasmic reticulum stress. Cell Biol Int 40: 289-297, 2016.

21. Cao K, Qian W, Xu Y, Zhou Z, Zhang Q and Zhang XF: A new sesquiterpenoid from Saussurea lappa roots. Nat Prod Res 30: 2160-2163, 2016

22. Utsugi T, Schroit AJ, Connor J, Bucana CD and Fidler IJ: Elevated expression of phosphatidylserine in the outer membrane leaflet of human tumor cells and recognition by activated human blood monocytes. Cancer Res 51: 3062-3066, 1991.

23. Adams JM and Cory S: The Bcl-2 apoptotic switch in cancer development and therapy. Oncogene 26: 1324-1337, 2007.

24. Riedl SJ and Shi Y: Molecular mechanisms of caspase regulation during apoptosis. Nat Rev Mol Cell Biol 5: 897-907, 2004.

25. Alves JCF: A review on the chemistry of eremanthine: A sesquiterpene lactone with relevant biological activity. Org Chem Int 2011: Article ID 170196, 2011.

26. Ramasamy K and Agarwal R: Multitargeted therapy of cancer by silymarin. Cancer Lett 269: 352-362, 2008.

27. López-Sáez JF, de la Torre C, Pincheira J and Giménez-Martín G: Cell proliferation and cancer. Histol Histopathol 13: 1197-1214, 1998.

28. Lin X, Peng Z, Fu X, Liu C, Xu Y, Ji W, Fan J, Chen L, Fang L, Huang Y and Su C: Volatile oil from Saussurea lappa exerts antitumor efficacy by inhibiting epithelial growth factor receptor tyrosine kinase-mediated signaling pathway in hepatocellular carcinoma. Oncotarget 7: 79761-79773, 2016.

29. Rasul A, Yu B and Yang LF, Arshad M, Khan M, Ma T and Yang $\mathrm{H}$ : Costunolide, a sesquiterpene lactone induces $\mathrm{G} 2 / \mathrm{M}$ phase arrest and mitochondria-mediated apoptosis in human gastric adenocarcinoma SGC-7901 cells. J Med Plants Res 6: 1191-1200, 2012.
30. Lau A, Wang Y and Chiu JF: Reactive oxygen species: Current knowledge and applications in cancer research and therapeutic. J Cell Biochem 104: 657-667, 2008.

31. Hengartner MO: The biochemistry of apoptosis. Nature 407: 770-776, 2000

32. Lang L, Zhu S, Zhang H, Yang P, Fan H, Li S, Liao Z, Lan X, Cui $\mathrm{H}$ and Chen $\mathrm{M}$ : A natural phenylpropionate derivative from Mirabilis himalaica inhibits cell proliferation and induces apoptosis in HepG2 cells. Bioorg Med Chem Lett 24: 5484-5488, 2014.

33. Gross A: Bcl-2 family proteins as regulators of mitochondria metabolism. Biochim Biophys Acta 1857: 1243-1246, 2016.

34. Elmore S: Apoptosis: A review of programmed cell death. Toxicol Pathol 35: 495-516, 2007.

35. Ko HM, Joo SH, Jo JH, Park WS, Jung WY, Shin JH and Ahn HJ: Liver-wrapping, nitric oxide-releasing nanofiber downregulates cleaved caspase-3 and bax expression on rat hepatic ischemia-reperfusion injury. Transplant Proc 49: 1170-1174, 2017.

36. Wurstle ML, Laussmann MA and Rehm M: The central role of initiator caspase-9 in apoptosis signal transduction and the regulation of its activation and activity on the apoptosome. Exp Cell Res 318: 1213-1220, 2012.

37. SalvesenGS: Caspase 8: Igniting the death machine. Structure 7: R225-R229, 1999.

38. Choi YK, Seo HS, Choi HS, Choi HS, Kim SR, Shin YC and Ko SG. Induction of Fas-mediated extrinsic apoptosis, p21WAF1-related G2/M cell cycle arrest and ROS generation by costunolide in estrogen receptor-negative breast cancer cells, MDA-MB-231. Mol Cell Biochem 363: 119-128, 2012.

39. Yi YI, Kim JH, Lee KT and Choi JH: Costunolide induces apoptosis in platinum-resistant human ovarian cancer cells by generating reactive oxygen species. Gynecol Oncol 123: 588-596, 2011.

40. Hua PY, Sun M, Zhang G, Zhang Y, Song G, Liu Z, Li X, Zhang X and $\mathrm{Li} \mathrm{B}$ : Costunolide induces apoptosis through generation of ROS and activation of P53 in human esophageal cancer Eca-109 cells. J Biochem Mol Toxicol 30: 462-469, 2016. 